\title{
Spontaneous Raman Scattering Temperature Measurements and Large Eddy Simulations of Vibrational Non-equilibrium in High-Speed Jet Flames
}

\author{
Heath H. Reising ${ }^{*}$, Timothy W. Haller ${ }^{*}$, Noel T. Clemens ${ }^{\dagger}$, and Philip L. Varghese \\ The University of Texas at Austin, Austin, TX 78712 \\ Romain Fiévet ${ }^{\S}$ and Venkat Raman** \\ The University of Michigan, Ann Arbor, MI 48109
}

\begin{abstract}
High-speed turbulent diffusion flames were investigated using time-averaged spontaneous Raman scattering to determine the vibrational and rotational temperature of the major diatomic species, $\mathbf{N}_{2}$ and $\mathrm{O}_{2}$. Mixing-induced thermal non-equilibrium is detected in the shear layer upstream of the turbulent hydrogen flame in $\mathrm{N}_{2}$ molecules but not $\mathrm{O}_{2}$. Rotational temperatures of the two species agree to within the measurement precision. The non-equilibrium is relaxed immediately beyond the average flame-base location due to the presence of combustion products. The non-equilibrium measured in a lower speed methanehydrogen flame is significantly weaker, as expected. The presence of non-equilibrium is confirmed using Rayleigh thermometry images to quantify the effect of translational temperature variation in the Raman measurement volume. The effect of interspecies vibrational energy transfer is investigated using large-eddy simulations of the experimental flow. Good agreement is found between the measurements and average simulated temperature fields when the interspecies vibrational coupling is very weak.
\end{abstract}

\section{Nomenclature}

$a=$ width of Lorentzian lineshape function

$b \quad=\quad$ base width of trapezoidal lineshape function

$d \quad=$ jet exit diameter

$E_{m} \quad=$ shear layer mass entrainment ratio

$G \quad=$ overall scaling factor of spectrum

$g_{s} \quad=$ nuclear spin degeneracy

$I_{\text {ref }} \quad=$ reference Rayleigh scattering intensity from known temperature gas

$I_{\text {Rayleigh }}=$ Rayleigh scattering intensity after background and reflection subtraction

$r \quad=$ shear layer velocity ratio, $u_{2} / u_{1}$

$\operatorname{Re}_{d} \quad=$ Reynolds number based on jet exit conditions

$s \quad=$ shear layer density ratio, $\rho_{2} / \rho_{1}$

\footnotetext{
* Graduate Research Assistant, Department of Aerospace Engineering and Engineering Mechanics, Austin TX, Student Member AIAA

$\dagger$ Bob R. Dorsey Professor in Engineering, Department of Aerospace Engineering and Engineering Mechanics, Austin TX, Associate Fellow AIAA

* Stanley P. Finch Centennial Professor in Engineering, Department of Aerospace Engineering and Engineering Mechanics, Austin TX, Associate Fellow AIAA

$\S$ Graduate Research Assistant, Department of Aerospace Engineering, Ann Arbor MI, Student Member AIAA

** Associate Professor, Department of Aerospace Engineering, Ann Arbor MI, Senior Member AIAA
} 


$\begin{array}{ll}S & =\text { lineshape function } \\ T_{r} & =\text { rotational temperature } \\ T_{V} & =\text { vibrational temperature } \\ t & =\text { top width of trapezoidal lineshape function } \\ Z_{s t} & =\text { stoichiometric mixture fraction } \\ \Phi_{x} & =\text { factor which accounts for space-averaged polarizability tensor } \\ v_{0} & =\text { frequency of incident light in } \mathrm{cm}^{-1} \\ v_{k} & =\text { Raman shift of spectral line, } k, \text { in } \mathrm{cm}^{-1}\end{array}$

\section{Introduction}

$\mathrm{T}$ hermal non-equilibrium is inherent in hypersonic engines. Shocks, isentropic compression/expansion, and viscous dissipation can lead to rapidly changing kinetic temperatures which requires changing population of higher vibrational levels and associated transfer of energy into or out of the vibrational mode to maintain thermal equilibrium. If the rate of change of kinetic temperature outpaces the rate at which molecular collisions can exchange energy between modes, a local non-equilibrium state will be produced. While rotational-to-translational (R-T) energy transfer may take only a few nanoseconds, vibrational-to-translational (V-T) energy transfer tends to require timescales on the order of microseconds to milliseconds. ${ }^{1}$ Owing to the short residence time of the gas in a scramjet combustor, any non-equilibrium generated by a rapid expansion or compression may persist throughout a significant portion of the engine. This excess/absence of energy in higher vibrational states can have a significant impact on the overall performance of the combustor through alteration of the chemical reaction rates or transport properties. Experimental studies have shown turbulence intensity and decay to be affected by plasma-generated V-T non-equilibrium. ${ }^{2}$ Similarly, Koo et al. $^{3}$ showed V-T non-equilibrium to alter jet flame stabilization heights in direct numerical simulations. They found that vibrational temperatures lower than translational hindered reactivity and pushed flame stabilization downstream. The simulations used a coupled-vibration-coupled-chemistry model which modified thermal equilibrium reaction rates with an efficiency function based on the vibrational and translational temperature of the reactants. ${ }^{4}$ When using this model, a single vibrational and a single translational temperature was assigned for all species, which ignores the complex effect internal state populations may play in chemical kinetics. Models that use state-specific rates, while much more computationally intensive, could provide insight into this behavior. Recent work in using quasi-classical trajectory analysis for hydrogen-air combustion reactions has shown the need for more detailed modeling of these flows. ${ }^{5}$ Detailed numerical simulations of a scramjet combustor with a hydrogen jet into supersonic cross-flow showed a surprising result: the effect of thermal non-equilibrium was to ignite and stabilize the flame closer to the injector. ${ }^{6}$

The current study employs a lifted high-speed jet flame in a hot coflow, which induces V-T non-equilibrium through rapid mixing in the shear layer upstream of the flame. Vibrational and rotational temperatures of $\mathrm{N}_{2}$ and $\mathrm{O}_{2}$ are measured using time-average spontaneous Raman scattering to quantify the magnitude of the non-equilibrium in various regions of the flow. Comparison between species temperatures will test the validity of modeling such a flow with a two-temperature model. Previous work on supersonic air jet mixing demonstrated the effectiveness of this technique in quantifying non-equilibrium in turbulent shear layers. ${ }^{7}$ The measurements are also compared with large eddy simulations of a similar jet flame with vibrational non-equilibrium.

\section{Experimental Apparatus}

\section{A. High-Speed Jet in Coflow Facility}

The jet facility consisted of an axisymmetric nozzle centered in a heated coflow. The converging subsonic nozzle had an exit diameter of $8 \mathrm{~mm}$, and the jet gases were supplied by compressed gas cylinders. The exit diameter of the coflow section was $100 \mathrm{~mm}$, and the low speed $(\sim 1 \mathrm{~m} / \mathrm{s})$ coflow air was supplied by a centrifugal blower. The coflow air was electrically heated by two $15 \mathrm{~kW}$ heaters to temperatures up to $1000 \mathrm{~K}$. The use of electric heaters (rather than vitiation) avoids the addition of water vapor into the coflow, since water is known to be an efficient relaxer of vibrational energy. ${ }^{8}$ The jet gases were heated by a pair of $6 \mathrm{~kW}$ electric heaters for precise control of the jet stagnation temperature.

For the current study, several flame conditions were run, which are summarized in Table 1 below. For each run, the coflow temperature was kept at $1000 \mathrm{~K}$. The jet velocity values in Table 1 are calculated based on input mass flow rates and thermocouple measurements. Flow rates were chosen such that the flame stabilized at approximately 
the same height in each case. Each of these conditions provided a flame which autoignited immediately upon the start of fuel flow. Figure 1 shows the average lifted flame location for the $\mathrm{H}_{2} / \mathrm{N}_{2}$ flame case as marked by a long exposure $\mathrm{OH}^{*}$ chemiluminescence image. The flame lifts approximately 5 diameters from the nozzle exit in this case and is highly turbulent.

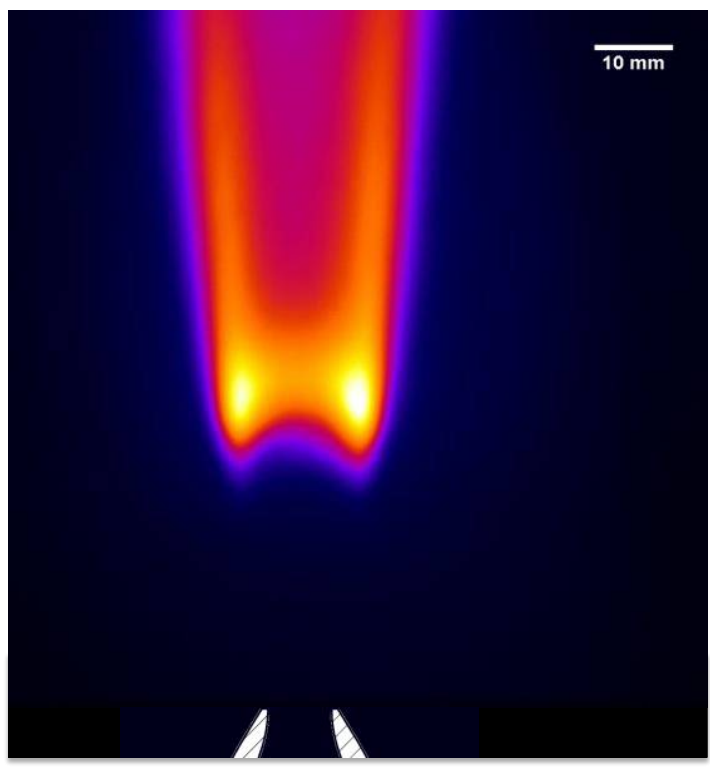

Figure 1. Image of $\mathrm{OH}^{*}$ chemi-luminescence for the $\mathrm{H}_{2} / \mathrm{N}_{2}$ flame

\begin{tabular}{ccccccc}
\multicolumn{7}{c}{ Table 1. Summary of flame run conditions } \\
Case & Jet (by mol.) & Coflow & $U_{\text {jet }}[\mathrm{m} / \mathrm{s}]$ & $R e_{d}$ & $T_{\text {o,jet }}[\mathrm{K}]$ & $Z_{\text {st }}$ \\
\hline $\mathrm{H}_{2} / \mathrm{N}_{2}$ & $68 \% \mathrm{H}_{2}, 32 \% \mathrm{~N}_{2}$ & Air & 540 & 75,100 & 560 & 0.181 \\
$\mathrm{H}_{2} / \mathrm{Ar}$ & $75 \% \mathrm{H}_{2}, 25 \% \mathrm{Ar}$ & Air & 505 & 77,000 & 570 & 0.183 \\
$\mathrm{H}_{2} / \mathrm{CH}_{4}$ & $62 \% \mathrm{H}_{2}, 38 \% \mathrm{CH}_{4}$ & Air & 300 & 27,400 & 550 & 0.048
\end{tabular}

\section{B. Spontaneous Raman Scattering Technique}

Stokes Raman scattering from $\mathrm{N}_{2}$ and $\mathrm{O}_{2}$ molecules was collected at high dispersion to obtain species-specific rotational and vibrational temperatures. Excitation was provided by a frequency-doubled Nd:YLF laser with an average power of $60 \mathrm{~W}$ at a $5 \mathrm{kHz}$ repetition rate. Owing to the weak nature of Raman scattering, a pair of $\mathrm{f} / 2.2150 \mathrm{~mm}$ diameter achromatic lenses was used to collect signal from a large scattering solid angle and relay the light into the Kaiser Optical Systems spectrograph. Spectra are imaged with PIMAX3 ICCD camera with an $18 \mathrm{~mm}$ wide Gen III intensifier, which gives a spectral coverage of 588 to $611 \mathrm{~nm}$ and 562 to $583 \mathrm{~nm}$ for the $\mathrm{N}_{2}$ and $\mathrm{O}_{2}$ measurements, respectively. The corresponding spectral dispersion at the sensor

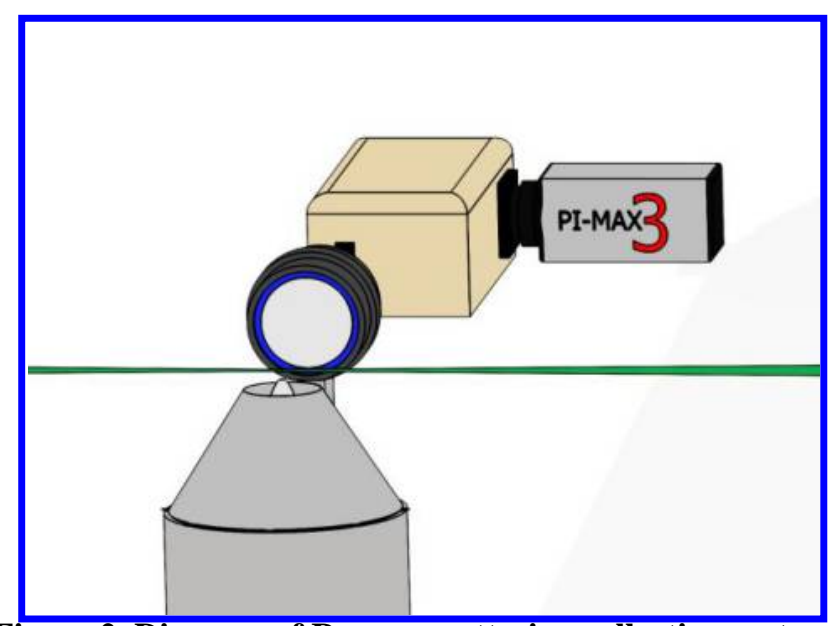

Figure 2. Diagram of Raman scattering collection system is 0.034 and $0.031 \mathrm{~nm}$ per pixel. A slit width of $100 \mu \mathrm{m}$ and a measured magnification of 1.4 provided an approximate measurement volume of $0.5 \mathrm{~mm} \times 0.5 \mathrm{~mm} \times 140 \mu \mathrm{m}$, with the smaller dimension being along the 
direction of beam propagation. Temperature profiles were taken along the beam direction to take advantage of the better spatial resolution.

\section{Rayleigh Thermometry}

The fuel composition in the $\mathrm{H}_{2} / \mathrm{CH}_{4}$ case was chosen such that it has approximately the same Rayleigh crosssection as air for all values of mixture fraction. ${ }^{9}$ With a constant cross-section, the scattered light only varies with gas number density, which allows us to relate the Rayleigh scattering signal to gas temperature through the following relation:

$$
T=\frac{T_{\text {ref }} I_{\text {ref }}}{I_{\text {Rayleigh }}}
$$

where the reference signal is taken from uniform scattering from room temperature $\left(T_{r e f}\right)$ air before each run.

The $532 \mathrm{~nm}$ incident light was provided by a frequency doubled Nd:YAG laser (Continuum Powerlite DLS 9010) at $10 \mathrm{~Hz}$ and $1 \mathrm{~J}$ per pulse. The laser light was focused into a sheet using a single $1 \mathrm{~m}$ focal length cylindrical lens. The scattered light was imaged with a CCD camera (PCO 1400) using a $50 \mathrm{~mm} \mathrm{f} / 1.2$ lens with $20 \mathrm{~mm}$ of extension. The signal was binned $2 \times 2$ on the sensor to increase the signal-to-noise ratio. The field of view was approximately $17 \mathrm{~mm}$ in the radial direction and $10 \mathrm{~mm}$ in the axial direction.

\section{Experimental Results}

\section{A. Raman Scattering Data Processing}

To extract scalar temperature values from the collected images, the spectra were calibrated spectrally and adjusted for variation in collection system spectral sensitivity. Spectral calibration was performed using a neon emission lamp that provided strong lines at known wavelengths. System response was calibrated by taking a spectrum of a CI Systems SR-20 blackbody cavity emitter at $1473 \mathrm{~K}$ and scaling by the expected Planck function at that temperature.

Vibrational and rotational temperatures are calculated from the spectra by fitting to a simulated spectrum using a Levenberg-Marquardt algorithm to obtain the least-square error. ${ }^{10}$ All distributions are assumed to be Boltzmann in order to infer a single temperature for each mode. The theoretical Raman spectrum at a given wavelength is given by $^{11}$

$$
I(\lambda)=\frac{G}{T_{r}}\left[v_{0}-v_{k}(v, J)\right]^{4} g_{s}(J) \frac{(2 J+1) e^{-\frac{h c E_{v}(v)}{k T_{v}} e^{-\frac{h c E_{r}(v, J)}{k T_{r}}}}}{Q\left(T_{v}, T_{r}\right)} \Phi_{x}(v, J) S\left(\lambda ; \lambda_{k}(v, J), b, a, t\right)
$$

Spectra taken in the coflow and shear layer are shown in Fig. 3 to illustrate typical equilibrium and nonequilibrium spectra, respectively. The spectra are integrated on the sensor for 8 or $12 \mathrm{~s}$ per measurement for $\mathrm{N}_{2}$ and $\mathrm{O}_{2}$, respectively, to obtain adequate signal-to-noise ratio in the weak rotational lines. The collected spectra contain sufficient detailed information in the rotational lines to provide independent measures of vibrational and rotational temperature. Raman shifts for the $\mathrm{O}_{2}$ spectra are small enough that interference from the $\mathrm{S}(5)$ and $\mathrm{S}(6) \mathrm{H}_{2}$ rotational lines is present in the shear layer. These lines are masked off, as seen in Fig. 4d, before applying the spectral fitting code used to infer temperatures. 
a)

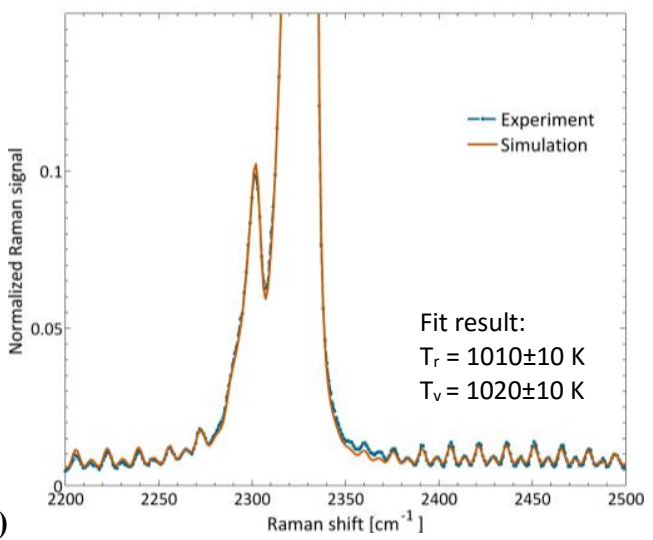

c)

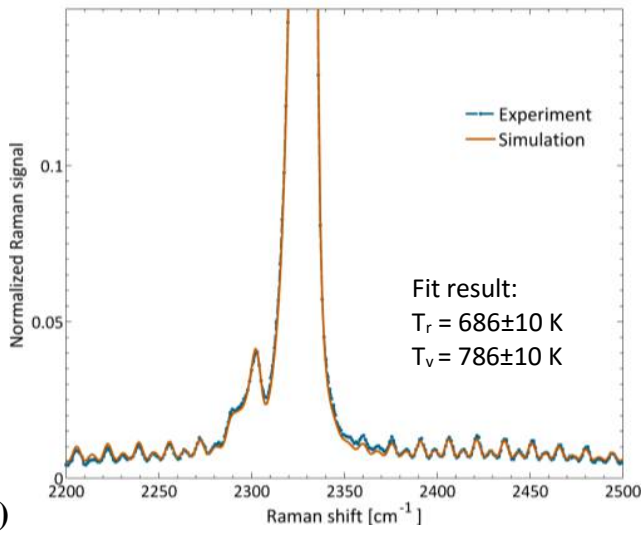

b)

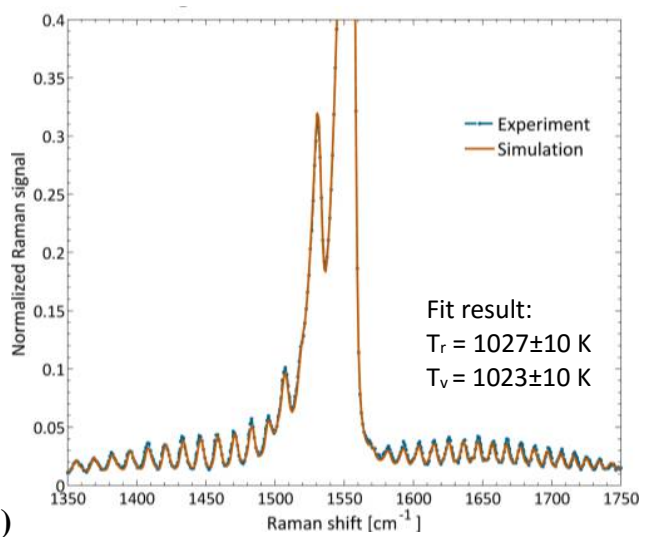

d)

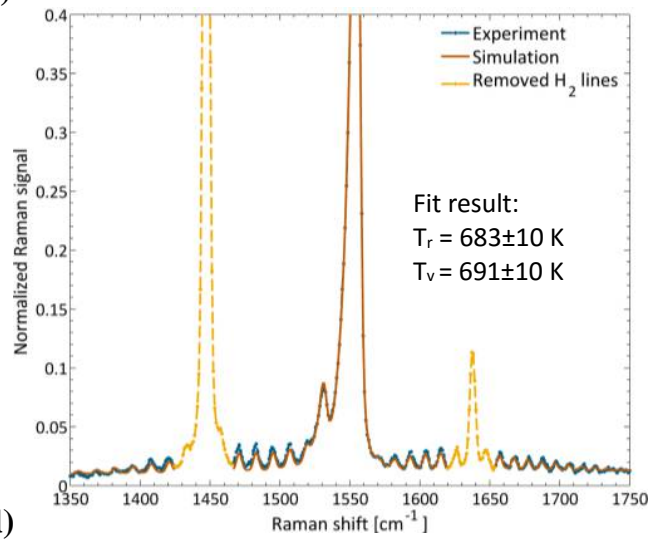

igure 3. Sample Raman scattering spectra and simulations at their fitted temperatures in coflow (a,c) and shear layer (b,d). Measurements were all taken at an axial distance of $2 d$ downstream of the nozzle in the preflame region.

\section{B. Presence of Non-Equilibrium in Measured Spectra}

Non-reacting shear layer studies were carried out on this facility in order to confirm the presence of nonequilibrium. ${ }^{7}$ In that study the Raman measurements could be confirmed with the use of Rayleigh thermometry due to the use of a single gas composition in both the jet and coflow. The same analysis can be applied to the current $\mathrm{H}_{2} / \mathrm{CH}_{4}$ Rayleigh thermometry results to confirm that temperature variation within the measurement volume does not contribute significant error to the fit result. Temperature values for regions of the flowfield of the same physical dimension as the Raman measurement are extracted from a set of 1000 Rayleigh images. The probability density function (pdf) within each of these regions is shown in Fig. 4. Equilibrium Raman spectra are calculated and summed to simulate the spatial and temporal averaging that occurs during a Raman measurement. The resultant composite spectra are then fitted for vibrational and rotational temperatures, which are also presented for each location in Fig. 4. As in the previous work, the temperature distributions are not broad enough to significantly affect the fit results. The maximum discrepancy between $T_{V}$ and $T_{R}$ is at most $15 \mathrm{~K}$, which is significantly less than the magnitude of non-equilibrium seen in the collected spectra; however, this is not expected to be the case in a region over which the flame is only present occasionally. Figure 5 shows sample Rayleigh thermometry images from the $\mathrm{H}_{2} / \mathrm{CH}_{4}$ flame, which illustrate the highly intermittent nature of the flame. The flame liftoff fluctuates over a distance that is larger than the imaging field of view. A time-averaged Raman measurement made in this region would be integrating over gas temperature changes of over $1000 \mathrm{~K}$ and could not be used to detect vibrational nonequilibrium. 


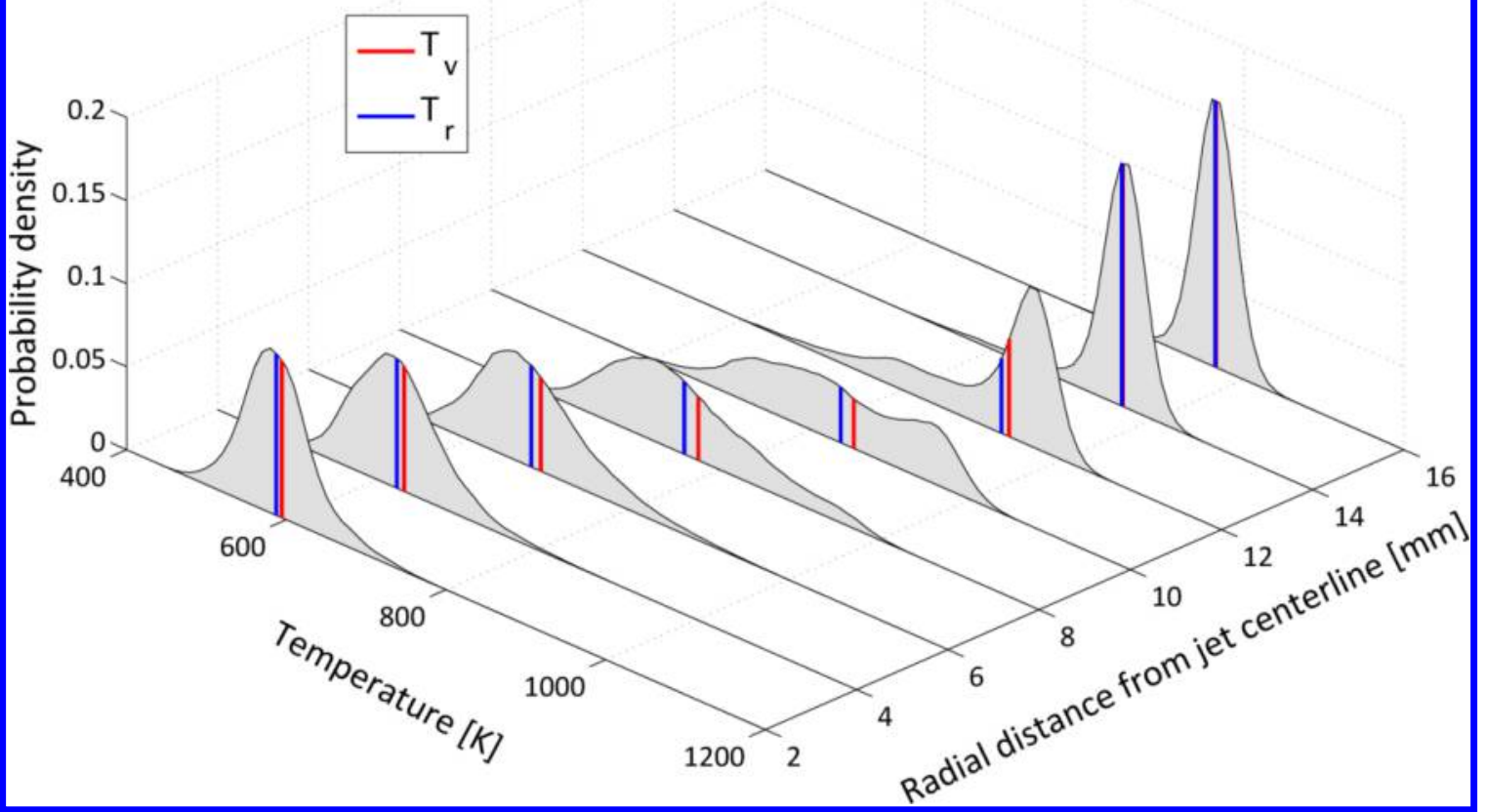

Figure 4. Temperature probability density functions extracted from Rayleigh thermometry images along with resultant temperatures from applying the fitting code to similarly distributed equilibrium spectra. The profile shown is 6 diameters downstream of nozzle exit

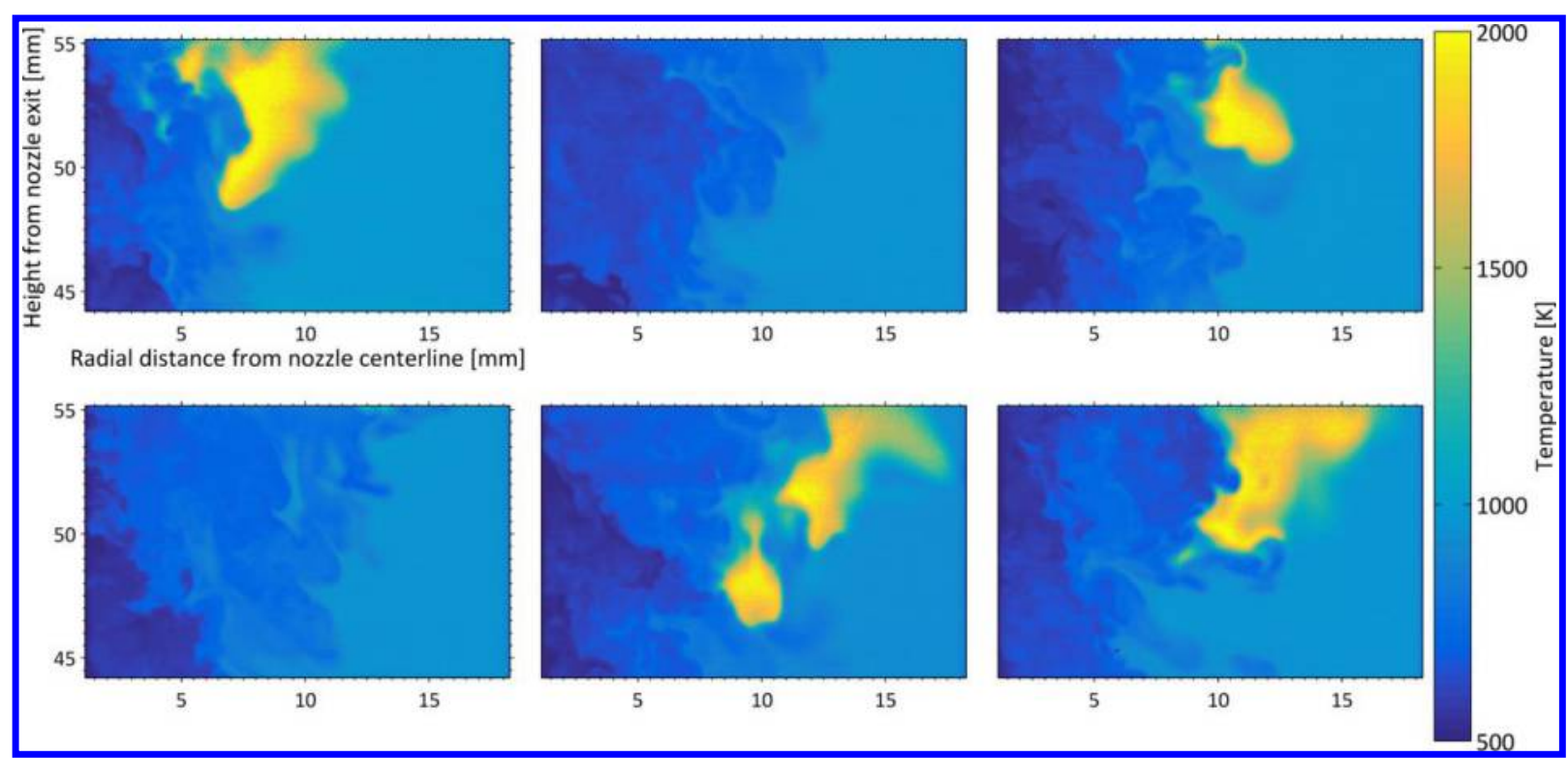

Figure 5. Subset of Rayleigh thermometry images for $\mathrm{H}_{2} / \mathrm{CH}_{4}$ flame

6

American Institute of Aeronautics and Astronautics 


\section{Measurements in Hydrogen Flames}

Using hydrogen as fuel simplifies the combustion chemistry and allows for simpler models to be used for CFD validation. The lack of carbon-containing polyatomic species also significantly simplifies the modeling of V-V and V-T energy transfer. Radial shear layer profiles were taken at various downstream locations to characterize the non-equilibrium in the shear layer upstream of the flame. Figure 7 a shows vibrational and rotational temperature measurements at a location upstream of the lowest extent of the unsteady flame base. The rotational temperatures of $\mathrm{N}_{2}$ and $\mathrm{O}_{2}$ agree very well, because R-T equilibration is very fast. This consistency between measurements, which were performed with separate runs, and using a different spectral region, provides verification of the measurement accuracy. From the vibrational temperature measurements in Fig. $7 \mathrm{a}$ it is apparent that the $\mathrm{N}_{2}$ is out of thermal equilibrium, as seen in our previous measurements ${ }^{7}$, but interestingly the $\mathrm{O}_{2}$ seems to be in complete equilibrium throughout the mixing layer. This would suggest that the V-V

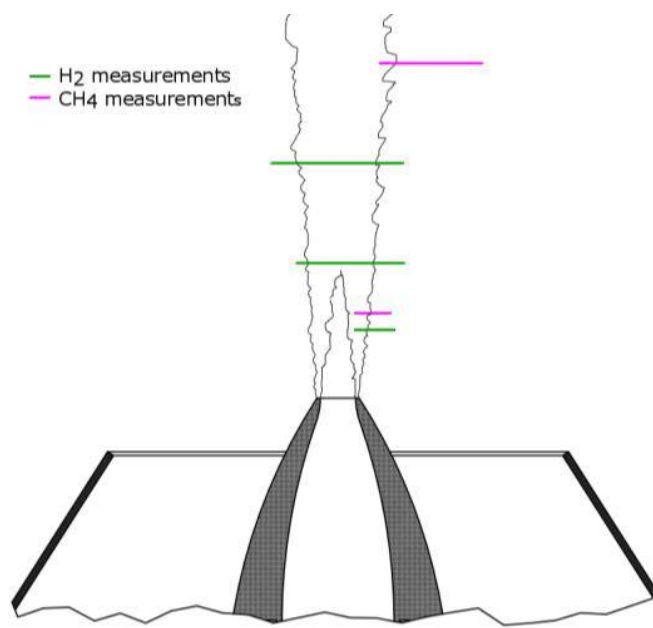

Figure 6. Schematic of Raman measurement locations (to scale) intermolecular transfer between these two species is very inefficient, which would lead to each species relaxing at its own V-T rate. This agrees with the study of Cutler et al. ${ }^{12}$, who found that $T_{v, \mathrm{~N}_{2}}$ and $T_{v, \mathrm{O}_{2}}$ were quite different in the non-equilibrium flow exiting a Mach 2 heated wind tunnel nozzle.

The error bars in the figure indicate the precision uncertainty (95\% confidence), and were determined using repeated measurements. Measurements are presented for radial locations where the signal-to-noise ratios are high enough that accurate fits could be made. In the near field, where there is still a potential core, there is no $\mathrm{O}_{2}$ in the jet fluid, and so the $\mathrm{O}_{2}$ Raman signals diminish faster than the $\mathrm{N}_{2}$ signals as the probe volume is translated toward the jet axis.

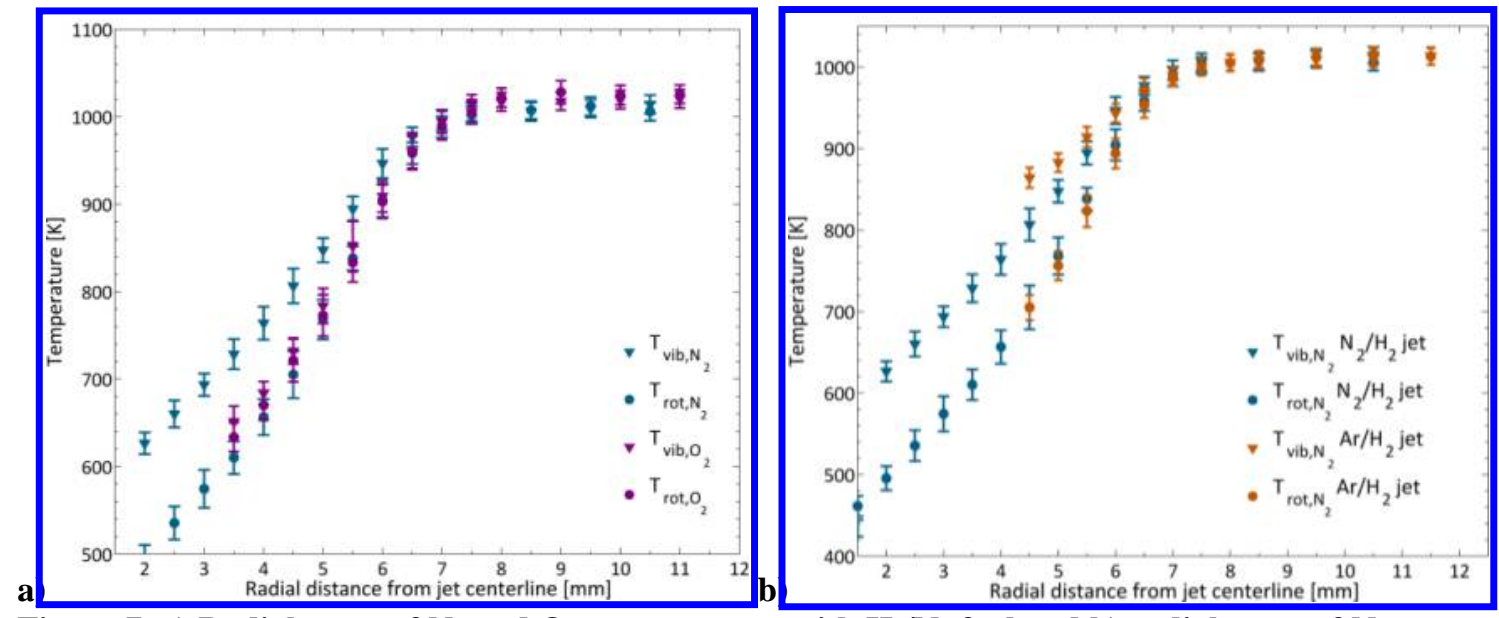

Figure 7. a) Radial trace of $\mathrm{N}_{2}$ and $\mathrm{O}_{2}$ temperatures with $\mathrm{H}_{2} / \mathrm{N}_{2}$ fuel and b) radial trace of $\mathrm{N}_{2}$ temperatures with $\mathbf{H}_{2} / \mathbf{N}_{2}$ and $\mathbf{H}_{2} / \mathbf{A r}$ fuel. Measurements were all taken at an axial distance of 2 jet diameters downstream of the nozzle in the pre-flame region.

The thermal energy transfer between the two streams by shear layer mixing is not as simple as it may appear. Cold and hot packets of fluid in thermal equilibrium originate on the high and low speed sides of the layer, respectively. The hot packets experience a rapid cooling while the cold packets experience a rapid heating. This creates two competing non-equilibrium processes. The replacement of $\mathrm{N}_{2}$ in the jet with Ar allows for the isolation of the hot-to-cold process as vibrationally cold $\mathrm{N}_{2}$ is no longer being provided on the high speed side. This effect is 
illustrated above in Fig. 7b. While the rotational temperatures for the two different jet compositions match well, the measured non-equilibrium is much stronger when there is no longer $\mathrm{N}_{2}$ present in the jet. Measurements with the $\mathrm{Ar}-\mathrm{H}_{2}$ jet are particularly difficult due to the lack of $\mathrm{N}_{2}$ from the high-speed side of the shear layer to provide scattered signal. This is why the profile for these runs does not extend as far into the jet.

The balance of the excitation/deexcitation processes is affected by ratio at which the shear layer entrains fluid from the high and low speed sides. If the entrainment is higher from one stream or the other, the vibrational temperature profile will be biased toward that side. The entrainment ratio of the shear layer can be predicted by the relation given by Dimotakis. ${ }^{13}$ Because the velocity ratio $(r)$ in our flow is very low, the relation simplifies to

$$
E_{m}(r \rightarrow 0)=\frac{1.68}{s^{1 / 2}}
$$

where $s$ is the density ratio across the shear layer. Values for freestream density and mass entrainment ratios are presented below in Table 2. If more mass from the cold jet is entrained $\left(E_{m}>1\right)$, the mixing layer temperature profile will be depressed such that the hot side will be further from the mean temperature. Molecules will tend to be vibrationally hot through a majority of the profile and vibrationally cold molecules will only be observed very near jet side of the layer. The hot-to-cold process dominates entrainment in all cases, which agrees with the behavior seen in the experimental shear layer profiles as well as the CFD results. However, the cold-to-hot process is still present and should influence the mean vibrational temperature profiles by reducing the apparent non-equilibrium measured, as seen in Fig. 7b.

Table 2. Shear layer density and mass entrainment ratios

\begin{tabular}{ccc} 
Case & $s$ & $E_{m}$ \\
\hline $\mathrm{H}_{2} / \mathrm{N}_{2}$ & 1.43 & 1.67 \\
$\mathrm{H}_{2} / \mathrm{Ar}$ & 1.31 & 1.75 \\
$\mathrm{H}_{2} / \mathrm{CH}_{4}$ & 2.14 & 1.37
\end{tabular}

The temperature profile at a location farther downstream is presented in Fig. 8. This location corresponds to the farthest downstream location where the flame is never present. At this location, the jet potential core is just collapsing as there is no flat section in the temperature profile corresponding to a region of pure jet fluid; therefore, the entire jet width can be probed since the $\mathrm{N}_{2}$-rich outer flow has penetrated to the center of the jet. The shear layer profiles on each side of the jet show similar behavior to the upstream profiles presented above, which is expected since this location is just beyond the shear layer region of the jet. It is important to note that non-equilibrium will not immediately disappear downstream of this point. The driving force behind non-equilibrium generation is the temperature gradient in the flow, which is still present beyond the potential core. The non-equilibrium will simply decay in magnitude as the jet centerline temperature rises to the outer flow temperature due to downstream turbulent mixing. This behavior is also observed in the simulation results presented in Fig. 12. It is shown there that nonequilibrium at the centerline begins near the collapse of the potential core and continues until far downstream where combustion products have been entrained to the jet centerline.

As mentioned previously, the current time-averaged measurement technique does not allow for meaningful measurements to be made in the region where the flame base is intermittently present. However, measurements can be taken downstream of this region. Results at such a downstream station are plotted in Fig. 9 below. The spectra for this axial location required a $15 \mathrm{~s}$ integration time in order to collect enough signal in the low-density flame region and in the $\mathrm{N}_{2}$-poor jet. The left hand figure shows a mean profile through both sides of the flame, which is seen to be symmetric, as expected. It is also clear that the non-equilibrium, which is seen in the non-reacting regions upstream, is completely gone at the location of peak temperature in the radial profile. This is expected as a high concentration of flame products such as $\mathrm{H}_{2} \mathrm{O}$ should quickly relax the non-equilibrium. Non-equilibrium is detected at the jet centerline just as it is in the upstream profile of Fig. 8. The simulation results of Fig. 12 show a similar nonequilibrium zone at the centerline around the height of the flame base. Figure $9 \mathrm{~b}$ shows a zoomed-in look at the peak temperature location. The peak measured temperature of $1835 \mathrm{~K}$ is $240 \mathrm{~K}$ less than the adiabatic flame temperature predicted for this fuel, which is reasonable considering the strained nature of the flame. The measured deviation from adiabatic flame temperature corresponds to a strain rate of $12,300 \mathrm{~s}^{-1}$ in a counterflow flame. ${ }^{14}$ 


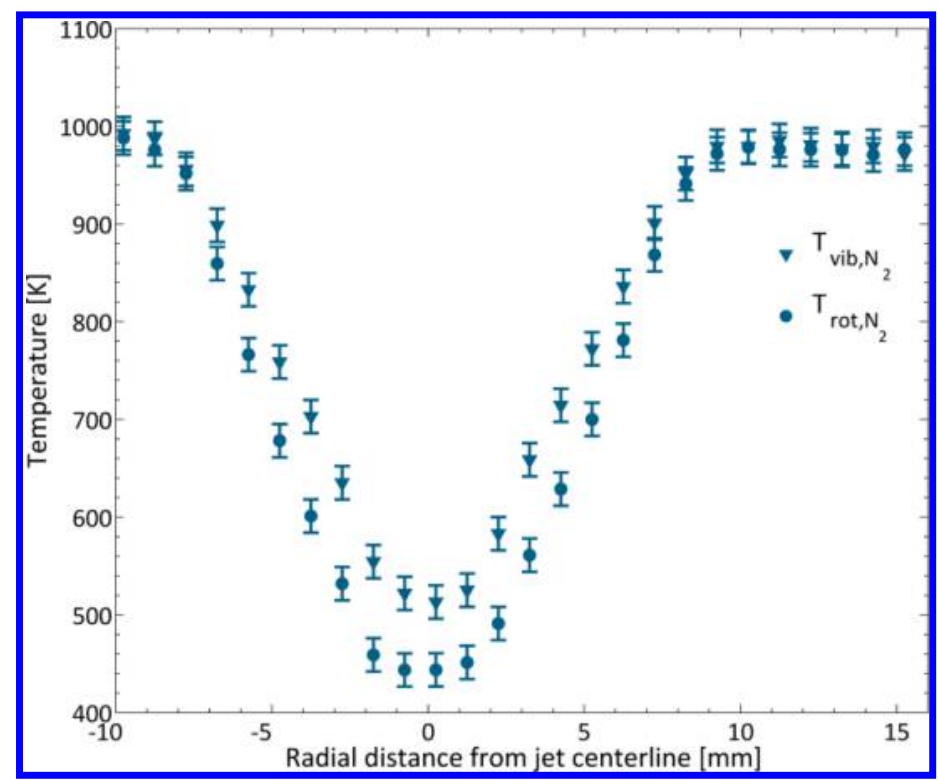

Figure 8. Radial mean profiles of $\mathrm{N}_{2}$ rotational and vibrational temperature approximately 4 diameters downstream of nozzle exit

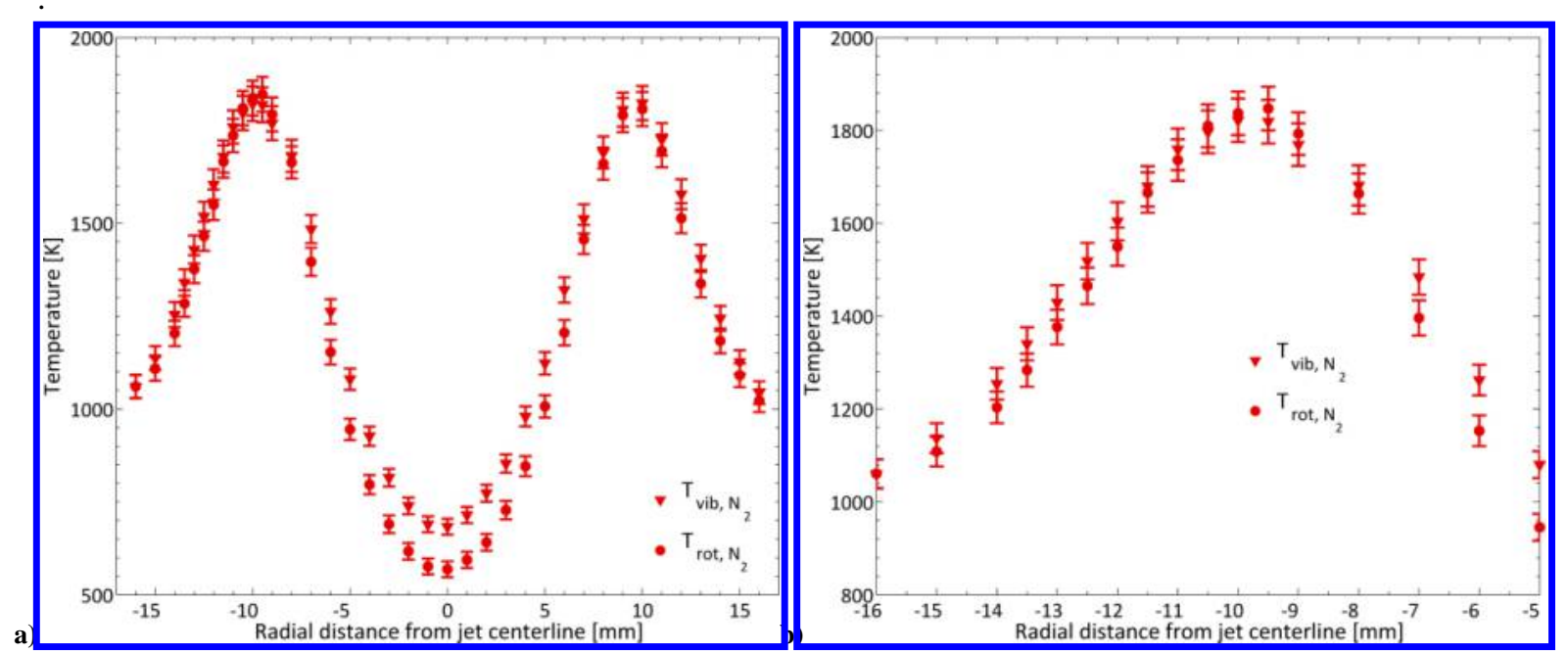

Figure 9. Radial trace of $\mathbf{N}_{2}$ temperatures 7 diameters downstream of nozzle exit (downstream of flame base) (a) Profile across entire flame, (b) zoomed-in view to show data near the peak temperature

\section{Measurements in Methane-containing Flames}

Figure 10a shows temperature profiles for the $\mathrm{H}_{2} / \mathrm{CH}_{4}$ jet at a location near to the nozzle exit. The nonequilibrium is clearly much weaker in this flow than in the hydrogen-containing cases. The lower level of nonequilibrium is most likely due to the much lower jet velocity that is required to prevent flame blowoff, although the inclusion of methane could also have had some effect on the relaxation process. Instead of reducing the jet velocity, the jet temperature could be increased to promote autoignition, but that would reduce the temperature difference between jet and coflow as a side-effect, and would reduce non-equilibrium strength. Like the $\mathrm{H}_{2} / \mathrm{Ar}$ jet case, this fuel mixture does not contain $\mathrm{N}_{2}$, which limits the depth into the jet that measurements can be made. 


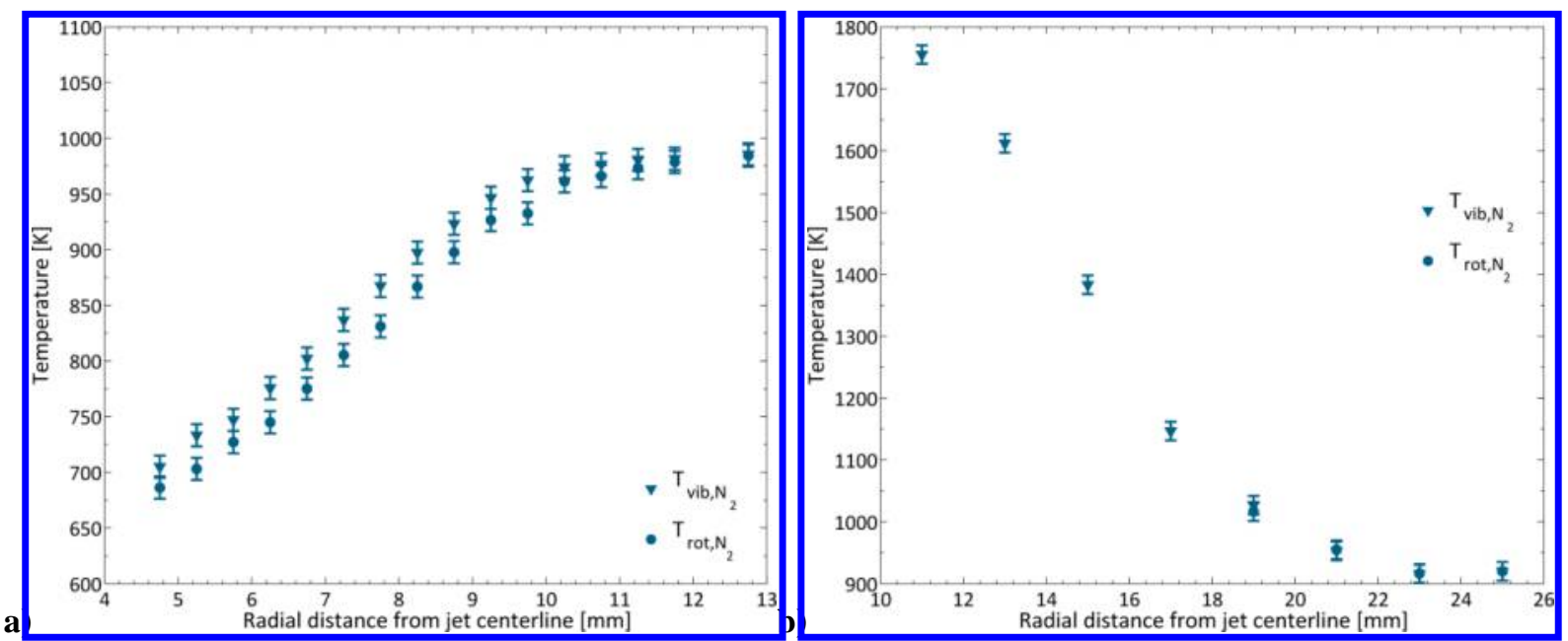

Figure 10. Radial trace of $\mathrm{N}_{2}$ temperatures a) 2.5 diameters downstream in the mixing layer and b) 10 diameters downstream

Results in the post-flame region are shown in Fig. 10b. Rotational temperatures could not be obtained for radial positions closer to the centerline than $19 \mathrm{~mm}$. The combined effect of an $\mathrm{N}_{2}$-free jet and the lower total number density in the high temperature region made rotational temperature fitting impossible even for spectra collected for as long as 42 seconds. Vibrational temperatures can be taken further into jet, but do not reach far enough into the jet to show the peak flame temperature. This illustrates the need for the presence of the Raman species being probed in both fuel and oxidizer streams for full profiles of flame temperature.

\section{Large-Eddy Simulations}

\section{A. Simulation Configuration}

The simulation was performed using the in-house compressible flow solver, UTComp, which has been previously used to simulate such non-equilibrium flows., ${ }^{3,6,15}$ The solver uses a fifth-order WENO scheme with characteristics reconstruction to compute the nonlinear fluxes while a fourth-order central scheme is used for the viscous and diffusion fluxes. The viscosity is determined using Sutherland's law and a constant Prandtl number of 0.72 is used to evaluate heat transfer. The simulation ran with a Courant-Friedrichs-Lewy number of roughly 0.9 , giving a time step of approximately $50 \mathrm{~ns}$. The code uses domain-decomposition based parallelization. A multitemperature model is implemented to quantify vibrational non-equilibrium, while the influence of vibrational nonequilibrium on combustion is computed in two steps. First, a 9-species 19-step chemistry model ${ }^{16}$ is used to compute the equilibrium rates. Then, a combination of rates derived from computational chemistry ${ }^{5,17}$ and from a coupled vibration-chemistry-vibration $(\mathrm{CVCV})$ reaction rate $\operatorname{model}^{4}$ are used to describe the deviation from the equilibrium rates. The solver equations are described in detail in Fiévet et al. ${ }^{6}$ Each simulation was run on 2000 cores for 8 hours until statistics were converged, on a $392 \times 320 \times 16$ structured cylindrical grid 20 jet diameters $(d)$ in length with a radius of $10 \mathrm{~d}$. The simulation used the same jet size as in the experiment, with a faster coflow of $30 \mathrm{~m} / \mathrm{s}$ for stability.

Table 3. Simulation conditions

\begin{tabular}{ccc} 
& Jet & Coflow \\
\hline Composition, by mole & $68 \% \mathrm{H}_{2}, 32 \% \mathrm{~N}_{2}$ & Air \\
$\mathrm{T}[\mathrm{K}]$ & 500 & 1000 \\
$\mathrm{~V}[\mathrm{~m} / \mathrm{s}]$ & 540 & 30
\end{tabular}

Average temperature fields from the simulation are shown below in Fig. 11. The simulation shows a mean liftoff height of approximately $12 d$, which is slightly larger than that observed in the experiment. This is due to the faster 
coflow in the simulation or differences in the velocity inflow boundary conditions. Figure 11 also indicates that the simulation predicts that $\mathrm{N}_{2}$ and $\mathrm{O}_{2}$ vibrational temperatures will stay in nearly complete equilibrium for these conditions. This directly contradicts the experimental findings already presented, where $\mathrm{N}_{2}$ was found to have a higher vibrational temperature than the gas temperature.

In the CVCV model for interspecies vibrational energy exchange, the probability factor sets how disparate the vibrational temperatures of different species will be. If the probability is high, the model will behave like a twotemperature system, while a low probability will cause each species to relax at its own V-T rate. For example, if the vibrational modes of $\mathrm{N}_{2}$ and $\mathrm{O}_{2}$ are relatively uncoupled, the $\mathrm{O}_{2}$ would be expected to move to equilibrium much faster as vibrational relaxation rate of $\mathrm{O}_{2}$ is expected to be at least an order of magnitude faster than $\mathrm{N}_{2}$ for all temperatures observed in this experiment. ${ }^{18}$

The factor used by Knab et al. was selected based on data for $\mathrm{V}-\mathrm{V}$ transfer at very high temperatures as they used the model for atmospheric re-entry simulations. In fact, the $\mathrm{V}-\mathrm{V}$ exchange probability for $\mathrm{N}_{2}-\mathrm{O}_{2}$ collisions has been found to be as low as $10^{-5}$ for the temperature range observed in this flow. ${ }^{19}$ This parameter requires further tuning to properly model the V-V transfer at the conditions currently being studied.
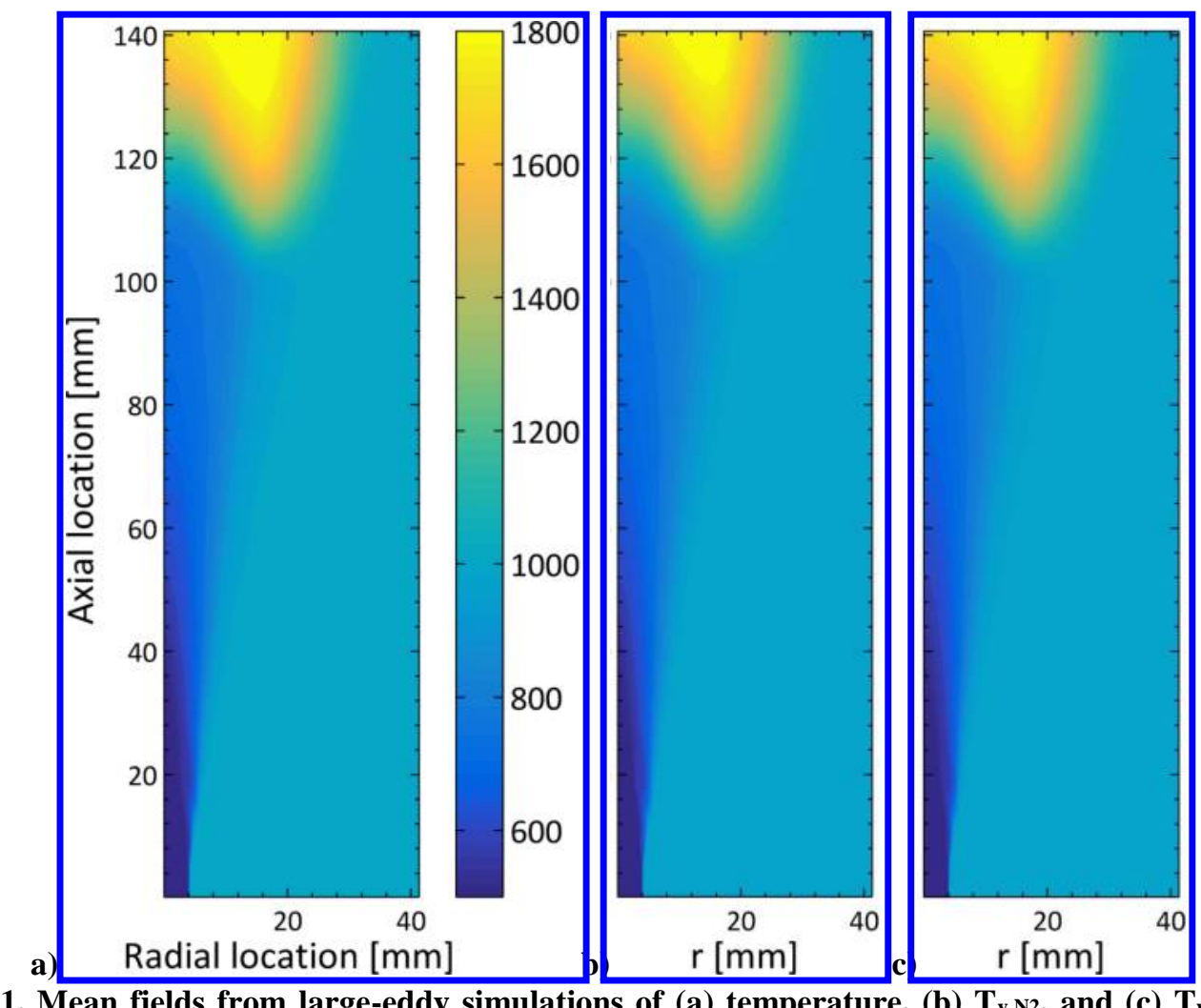

Figure 11. Mean fields from large-eddy simulations of (a) temperature, (b) $T_{v, N 2}$, and (c) $T_{v, 02}$ for an interspecies vibrational transfer probability of $10^{-2}$ given in Knab et al.

\section{B. Effect of Interspecies Vibrational Energy Transfer}

The influence of the vibrational exchange probability in the CVCV model on large-scale non-equilibrium behavior was investigated by logarithmic variation from $10^{-2}$ to $10^{-5}$. Parametric study is used because distilling multiple collision pair exchange probabilities (if known) over a range of temperatures to a single parameter would require a complex averaging procedure. Instead, macroscopic non-equilibrium behavior is compared with the Raman scattering measurements for determination of a suitable vibrational exchange parameter.

Figures 12 shows the non-equilibrium magnitude in $\mathrm{N}_{2}$ and $\mathrm{O}_{2}$ through the deviation of the mean vibrational temperature fields from the gas temperature for $\mathrm{P}_{\mathrm{v}-\mathrm{v}}$ of $10^{-2}$ (Figs. 12a and 12b) and $\mathrm{P}_{\mathrm{v}-\mathrm{v}}$ of $10^{-5}$ (Figs. 12c and 12d). As in Fig. 11, there is clearly no significant non-equilibrium in either $\mathrm{N}_{2}$ or $\mathrm{O}_{2}$ for the highly-coupled case. 
Conversely, the weakly coupled case shows non-equilibrium originating in the upstream mixing layer and persisting downstream toward the flame location. In the larger view of Fig. 13, it is seen that regions of the flow containing combustion products show minimal non-equilibrium just as in the experimental results due to the expected rapid quenching by $\mathrm{H}_{2} \mathrm{O}$ molecules

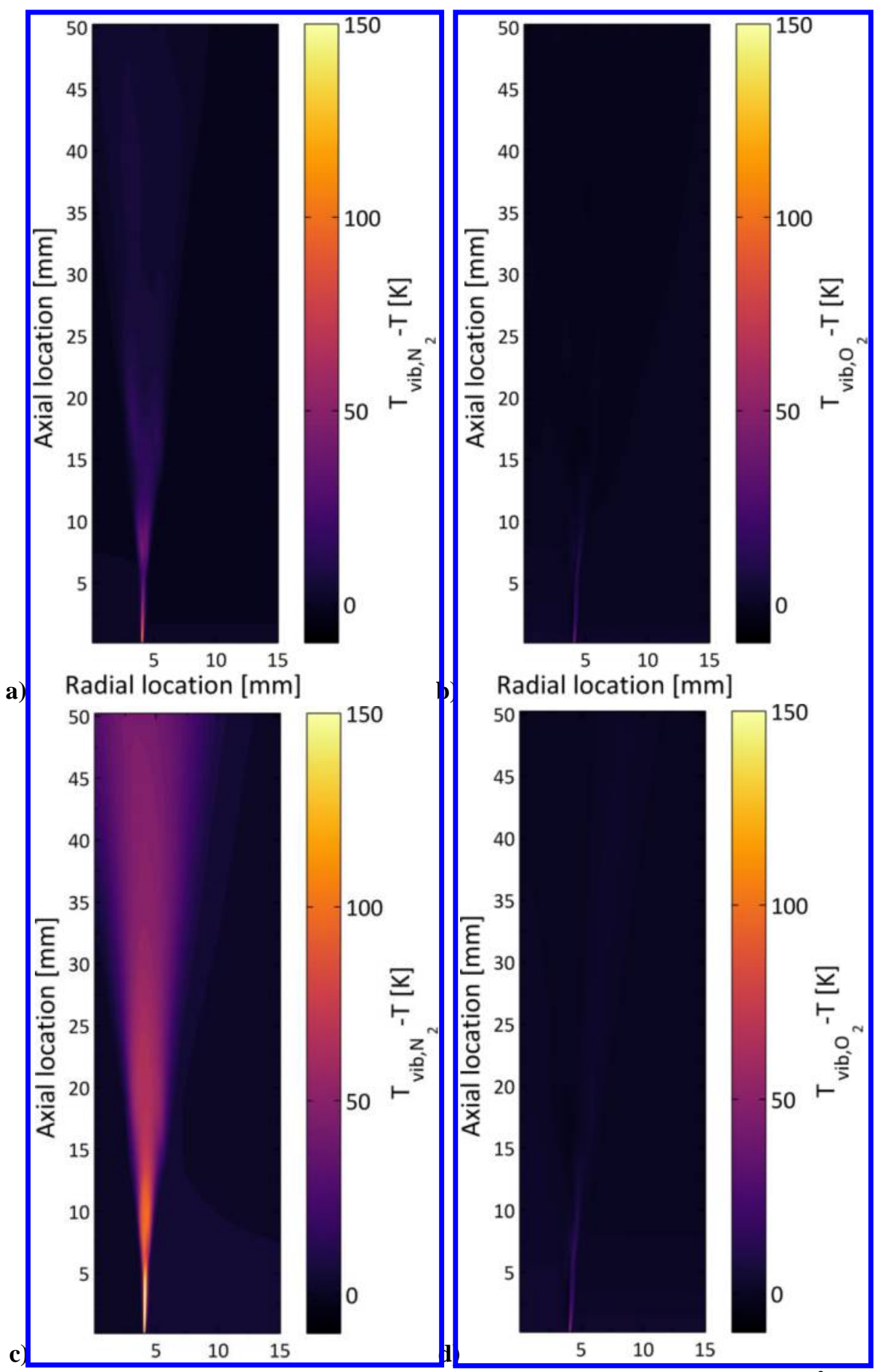

Figure 12. Mean non-equilibrium fields from large-eddy simulations for (a-b) $P_{v-v}=10^{-2}(c-d) P_{v-v}=10^{-5}$ in the near-field

American Institute of Aeronautics and Astronautics 


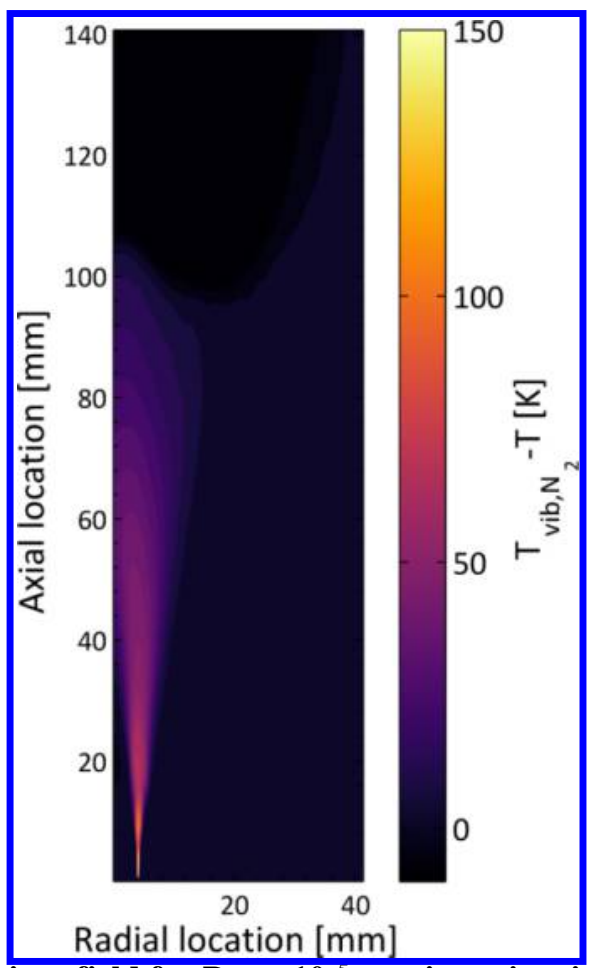

Figure 13. Mean $\mathrm{N}_{2}$ non-equilibrium field for $\mathrm{P}_{\mathrm{v}-\mathrm{v}}=10^{-5}$ case in entire simulation domain

The quantitative effect of this coupling parameter on non-equilibrium magnitude is further investigated by logarithmic variation between the two limiting cases shown above. As seen in Fig. 14 the largest change occurs between $\mathrm{P}_{\mathrm{v}-\mathrm{v}}=10^{-2}$ and $10^{-3}$ cases. As expected, the difference diminishes as the probability is lowered to a level where virtually no interspecies vibrational exchange occurs.
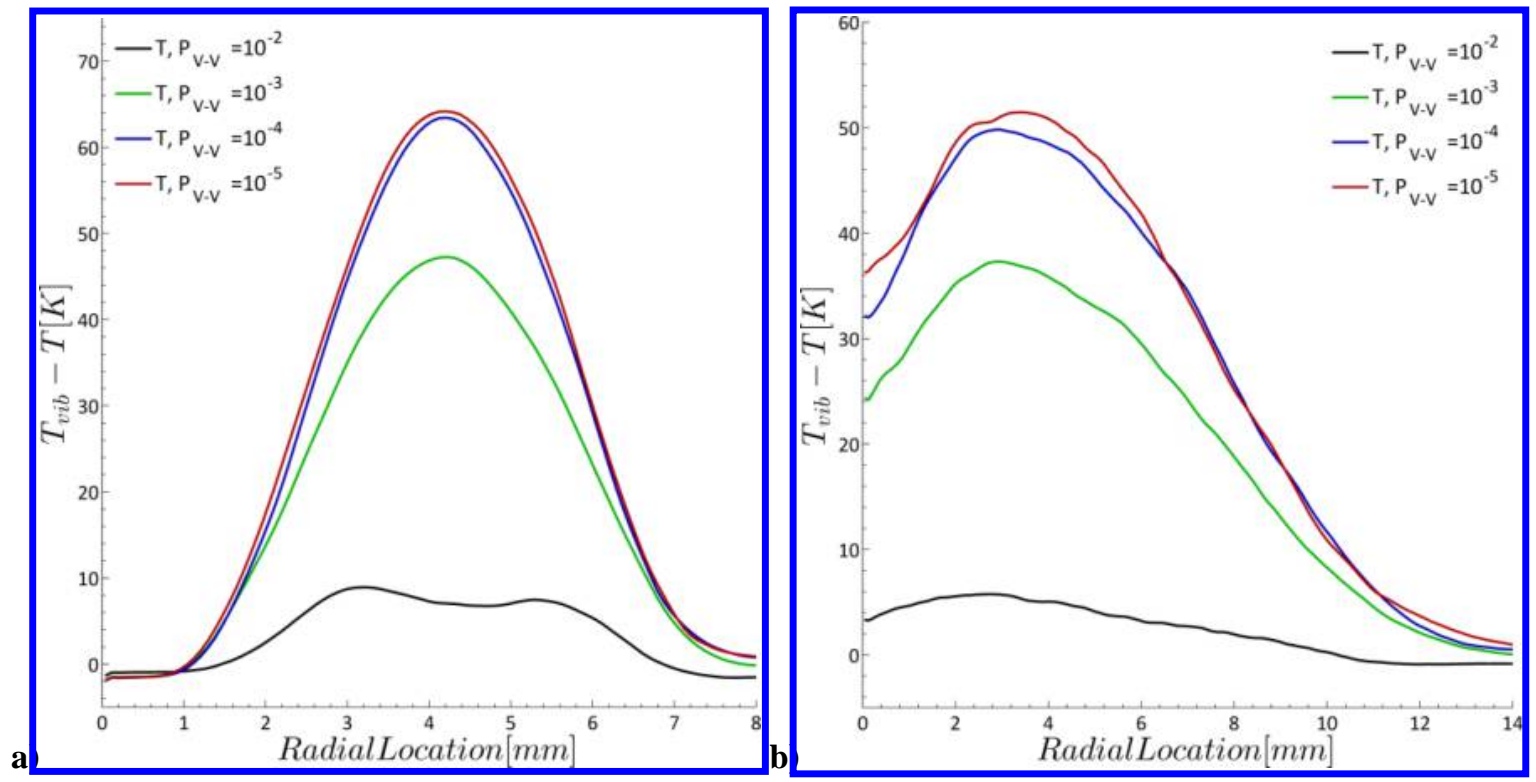

Figure 14. Radial profiles of $\mathrm{N}_{2}$ non-equilibrium magnitude for different $\mathrm{V}-\mathrm{V}$ probabilities (a) 25 $\mathrm{mm}$ and (b) $50 \mathrm{~mm}$ downstream of jet exit

American Institute of Aeronautics and Astronautics 
For comparison with the experiments, radial temperature profiles are extracted from the simulations at different downstream locations. Due to the difference in inflow conditions, the profiles are extracted at downstream locations which are the same fraction of the potential core length. Profiles are normalized by width and freestream temperature values in order to compare directly.

Figures 15 show comparisons between the experiment and simulation at two axial locations. The simulation case shown is for the weakest vibrational exchange probability $\left(10^{-5}\right)$. Good agreement is shown in between the experiment and simulation in the peak non-equilibrium magnitude at both axial stations. Both locations show a slightly stronger non-equilibrium in the experiments than in the simulations in the shear layer. This could be due to a difference in the nozzle velocity profile, which could strongly influence the shear layer behavior. The agreement of this case with the experimental results demonstrates that flows in this temperature regime have negligible vibrational coupling between species.
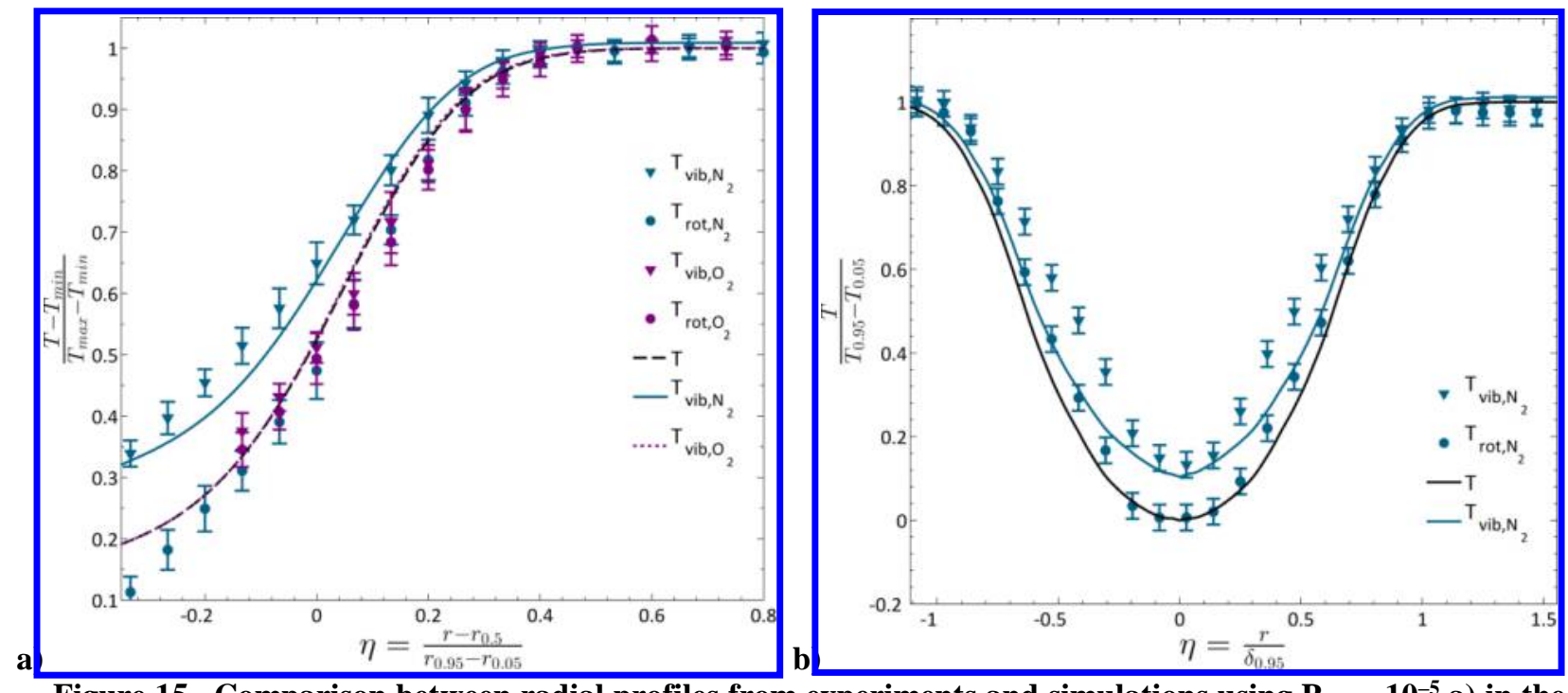

Figure 15. Comparison between radial profiles from experiments and simulations using $P_{v-v}=10^{-5}$ a) in the shear layer and b) at the location of potential core collapse. Discrete points denote measurements, while continuous lines signify simulation results.

\section{Conclusions}

Spontaneous Raman scattering has been demonstrated to be a useful technique in assessing species-specific thermal non-equilibrium in turbulent high-speed jet flames $\left(R e_{d}=27,000\right.$ to 77,000$)$. Fuel jets composed of $\mathrm{H}_{2} / \mathrm{N}_{2}$, $\mathrm{H}_{2} / \mathrm{Ar}$ and $\mathrm{H}_{2} / \mathrm{CH}_{4}$ were studied. The jets issue into a coflow of air heated to $1000 \mathrm{~K}$, the flames are lifted, and their stabilization is aided by autoignition. Measurements were made in the non-reacting shear layer upstream of the flame stabilization location and downstream of the stabilization location. In the $\mathrm{H}_{2} / \mathrm{N}_{2}$ fuel case, in the non-reacting shear layer, the rotational temperatures of $\mathrm{O}_{2}$ and $\mathrm{N}_{2}$ agree very well through the shear layer, even when data are taken days apart. Non-equilibrium between vibrational and rotational-translational states of $\mathrm{N}_{2}$ is shown to exist in the mixing region upstream of all the studied flames. There was no measurable vibrational non-equilibrium in the $\mathrm{O}_{2}$ molecules in the same non-reacting region. As expected, non-equilibrium was damped rapidly in the post-flame regions where water vapor is present.

Large-eddy simulations showed similar non-equilibrium behavior as observed in the experiment with the proper interspecies vibrational coupling parameter. This parameter is temperature-dependent and inherently averaged over all possible collision pairs, which makes a priori determination difficult. While this single-parameter vibrational transfer model could be replaced by models of increasing complexity using species-specific V-V probabilities or a master equation mechanism which models all state-to-state reactions individually, such models would make 3D simulations prohibitively expensive. This relatively cheap model is shown to reproduce the vibrational energy transfer seen experimentally with acceptable accuracy. 


\section{Acknowledgments}

This work was funded by the Air Force Office of Scientific Research under BRI grant FA9550-12-0460 with Dr. Ivett Leyva as the grant monitor.

\section{References}

1 Vincenti, W. G., and Kruger, C. H., Introduction to Physical Gas Dynamics, New York: John Wiley, 1965.

$\checkmark 2$ Fuller, T. J., Hsu, A., Sanchez-Gonzalez, R., Dean, J. C., North, S., and Bowersox, R. D. W., "Radiofrequency plasma stabilization of a low-Reynolds-number channel flow," Journal of Fluid Mechanics, vol. 748, 2014, pp. 663-691.

$\checkmark 3$ Koo, H., Raman, V., and Varghese, P. L., "Direct numerical simulation of supersonic combustion with thermal nonequilibrium," Proceedings of the Combustion Institute, vol. 35, 2015, pp. 2145-2153.

$\checkmark 4$ Knab, O., Fruehauf, H. H., and Messerschmid, E. W., "Theory and validation of the physically consistent coupled vibrationchemistry-vibration model," Journal of Thermophysics and Heat Transfer, vol. 9, 1995, pp. 219-226.

$\checkmark 5$ Voelkel, S. J., Raman, V., and Varghese, P. L., "Effect of thermal nonequilibrium on reactions in hydrogen combustion," Shock Waves, 2016.

6 Fiévet, R., Voelkel, S. J., Koo, H., Raman, V., and Varghese, P. L., "Effect of Thermal Nonequilibrium on Ignition in Scramjet Combustors," Proceedings of the Combustion Institute, Seoul, South Korea: 2016.

$\rightarrow 7$ Reising, H. H., Kc, U., Voelkel, S. J., Clemens, N. T., Raman, V., Varghese, P. L., and Koo, H., "Vibrational Non-equilibrium Effects in Supersonic Jet Mixing," 52nd AIAA Aerospace Sciences Meeting, 2014.

$\rightarrow 8$ Meador, W., Townsend, L., and Miner, G., "Effects of H2O vapor on vibrational relaxation in expanding and contracting flows," 34th Aerospace Sciences Meeting and Exhibit, 1996.

$\checkmark 9$ Dibble, R. W., and Hollenbach, R. E., "Laser rayleigh thermometry in turbulent flames," Symposium (International) on Combustion, vol. 18, Jan. 1981, pp. 1489-1499.

${ }^{10}$ Utsav, K. C., and Varghese, P. L., "Accurate temperature measurements in flames with high spatial resolution using Stokes Raman scattering from nitrogen in a multiple-pass cell.," Applied optics, vol. 52, Jul. 2013, pp. 5007-21.

$\checkmark{ }^{11}$ Long, D. A., The Raman Effect: A Unified Treatment of the Theory of Raman Scattering by Molecules, New York: John Wiley, 2002.

$\checkmark 12$ Cutler, A. D., Cantu, L. M. L., Gallo, E. C. A., Baurle, R., Danehy, P. M., Rockwell, R., Goyne, C., and McDaniel, J., "Nonequilibrium Supersonic Freestream Studied Using Coherent Anti-Stokes Raman Spectroscopy," AIAA Journal, vol. 53, 2015, pp. 1-9.

$>13$ Dimotakis, P. E., “Two-dimensional shear-layer entrainment," AIAA Journal, vol. 24, Nov. 1986, pp. 1791-1796.

${ }^{14}$ Goodwin, D. G., Moffat, H. K., and Speath, R. L., "Cantera: An object-oriented software toolkit for chemical kinetics, thermodynamics, and transport processes," 2015.

$\rightarrow 15$ Fievet, R., Koo, H., and Raman, V., "Numerical simulation of a scramjet isolator with thermodynamic nonequilibrium," 22nd AIAA CFD Conference, Dallas, TX: 2015.

16 Mueller, M. A., Kim, T. J., Yetter, R. A., and Dryer, F. L., "Flow Reactor Studies and Kinetic Modeling of the H2/O2 Reaction," International Journal of Chemical Kinetics, vol. 31, 1999, pp. 113-125.

$\checkmark{ }^{17}$ Voelkel, S. J., Raman, V., and Varghese, P. L., "Quasi-State-Specific QCT Method for Calculating the Dissociation Rate of Nitrogen in Thermal Non-Equilibrium," 54th AIAA Aerospace Sciences Meeting, 2016, pp. 1-16.

18 White, D. R., and Millikan, R. C., "Vibrational Relaxation in Air," AIAA Journal, vol. 2, 1964, pp. $1844-1846$.

19 Taylor, R. L., Camac, M., and Feinberg, R. M., "Measurements of Vibration-Vibration Coupling in Gas Mixtures," Symposium (International) on Combustion, vol. 11, 1967, pp. 49-65. 
This article has been cited by:

1. Timothy W. Haller, Heath H. Reising, Noel T. Clemens, Philip L. Varghese. High-Pressure Spontaneous Raman Scattering Based Temperature Measurements . [Citation] [PDF] [PDF Plus] 